\title{
New Iterative Method for Solution of System of linear Differential Equations
}

\author{
Muhammad Shafeeq ur Rehman ${ }^{1}$, M. Yaseen ${ }^{2}$, Tahir Kamran ${ }^{3}$ \\ ${ }^{1}$ Chenab college of Advanced studies Faisalabad (NCBA\&E), Faisalabad, Pakistan \\ ${ }^{2}$ University of Sargodha,Sargodha, Pakistan \\ ${ }^{3}$ Chenab college of Advanced studies Faisalabad (NCBA\&E), Faisalabad, Pakistan
}

\begin{abstract}
In this study new iterative method is used for the solution of system of linear differential equations. The solution is obtained in series form and then obtained the exact solution. This shows the efficiency of the new iterative method. Because using new iterative method we can find its solution easily and more accurately.
\end{abstract}

Keywords: Linear differential equations, New Iterative Method, scientific work place

\section{Introduction}

A differential equation is an equation involving dependent variable and independent variables and derivatives of one or more dependent variables with respect to one or more independent variables. An equation involving one or more derivatives of dependent variable with respect to single independent variable is called an ordinary differential equation.

An ODE is known as linear if:

1) The derivative of the dependent variable is one and also the power of the dependent variable is one.

2) The coefficient of the derivative and the coefficient of the dependent variable are constants or independent variables.

In this paper we have used new iterative method to solve linear differential equations which are already solved with differential transform method. N.Patil and A. khambayat [1] used differential transformation method to solve the equations.

\section{The New Iterative Method}

Consider the following general functional equation

$$
y(\bar{x})=f(\bar{x})+N(y(\bar{x})) \text {. }
$$

Where $\mathrm{N}$ is nonlinear from a Banach space $\mathrm{B} \rightarrow \mathrm{B}, \mathrm{f}$ is a known function and $\quad \bar{x}=\left(x_{1} x_{2}, \ldots \ldots \ldots, x_{n}\right)$. We are looking for a solution y of eq. (1) having the series form $y(\bar{x})=\sum_{n=0}^{\infty} y_{i}(\bar{x})$

The nonlinear operator $\mathrm{N}$ can be decomposed as

$$
N\left(\sum_{n=0}^{\infty} y_{i}\right)=N\left(y_{0}\right)+\sum_{i=1}^{\infty}\left\{N\left(\sum_{j=0}^{i} y_{j}\right)-N\left(\sum_{j=0}^{i-1} y_{j}\right)\right\}
$$

From Eqs. (2) And eq (3), Eq. (1) is equivalent to

$\sum_{i=0}^{\infty o} y_{i}=f+N\left(y_{0}\right)+\sum_{i=1}^{\infty o w}\left\{N\left(\sum_{j=0}^{i} y_{j}\right)-N\left(\sum_{j=0}^{i-1} y_{j}\right)\right\}$.

We define the recurrence relation as $y_{0}=f_{x}$

$y_{1}=N\left(y_{0}\right)$,

$y_{m+1}=N\left(y_{0}+\cdots+y_{m}\right)-N\left(y_{0}+\cdots+y_{m-1}\right)$

Then

$\left(y_{1}+\cdots+y_{m+1}\right)=N\left(y_{0}+\cdots+y_{m}\right)$.

And

$$
\sum_{i=0}^{\infty} y_{i}=f+N\left(\sum_{i=0}^{\infty} y_{i}\right)
$$

The L-term approximation solution of Eq. (1) is given by $y=y_{0}+y_{1}+\cdots+y_{k-1}$

If $\mathrm{N}$ contracts i.e. $\|N(x)-N(y)\| \leq L\|x-y\|, 0<L<1_{x}$ then

$\left\|\mathrm{y}_{\mathrm{m}+1}\right\|=\| \mathrm{N}\left(\mathrm{y}_{0}+\cdots+\mathrm{ys}_{\mathrm{m}}\|-\mathrm{N}\| \mathrm{y}_{0}+\cdots+\mathrm{y}_{\mathrm{m}-1}\|\leq \mathrm{L}\| \mathrm{y}_{\mathrm{m}}\left\|\leq \mathrm{L}^{\mathrm{m}}\right\| \mathrm{y}_{0} \|, \mathrm{m}=0,1,2 \ldots \ldots\right.$

And series $\sum_{i=0}^{\infty} y_{i}$ uniformly and absolutely converges to solution of equation (1). A unique solution, with respect to Banach fixed point theorem [12].

\section{Numerical Examples}

Example 1; Consider this system of simultaneous linear differential equations

$$
\begin{aligned}
& \frac{d x}{d t}-2 x+3 y=0, \\
& \frac{d y}{d t}+2 x-y=0,
\end{aligned}
$$

The conditions are as
The corresponding integral equations are as follows

$$
\begin{aligned}
& x(t)=8+\int_{0}^{t}(2 \mathrm{x}-3 \mathrm{y}) \mathrm{dt} \\
& y(t)=3+\int_{0}^{\mathrm{t}}(-2 \mathrm{x}+\mathrm{y}) \mathrm{dt} \\
& \text { Setting } x_{10}=8_{0} y_{20}=3 \text { and } \\
& N_{1}\left(x_{10}, y_{20}\right)=\int_{0}^{t}(2 \mathrm{x}-3 \mathrm{y}) \mathrm{dt}, N_{2}\left(x_{10}, y_{20}\right)=\int_{0}^{\mathrm{t}}(-2 \mathrm{x}+\mathrm{y}) \mathrm{dt}
\end{aligned}
$$

Following the algorithm of NIM we obtain following approximations:

$\mathrm{x}_{11}=N_{1}\left(x_{10}, y_{20}\right)=7 \mathrm{t}$ 
$y_{21}=N_{2}\left(x_{10}, y_{20}\right)=-13 \mathrm{t}$

$\mathrm{x}_{12}=\frac{53}{2} t^{2}$

$\mathrm{y}_{22}=\frac{-27}{2} t^{2}$

$\mathrm{x}_{1 \mathrm{a}}=\frac{187}{6} t^{\mathrm{a}}$

$\mathrm{y}_{2 \mathrm{a}}=\frac{187}{6} t^{\mathrm{a}}$

The solution in the series form is

$x(t)=8+7 t+\frac{53}{2} t^{2}+\frac{187}{6} t^{2}$

$y(t)=3-13 t-\frac{27}{2} t^{2}-\frac{133}{6} t^{3}$

Example 2; Consider this system of simultaneous linear differential equations

$\frac{d x}{d t}-y=e^{t}$
$\frac{d y}{d t}+x=\sin t$

And the initial conditions are $x(0)=1, y(0)=0$

The corresponding integral equations are as follows

$x(t)=8+\int_{0}^{t}(2 x-3 y) d t$

$y(t)=3+\int_{0}^{t}(-2 x+y) d t$

Setting $x_{10}=e^{t}, y_{20}=1-$ cost, and

$N_{1}\left(x_{10}, y_{20}\right)=\int_{0}^{\mathrm{t}} \mathrm{y}(\mathrm{t}) \mathrm{dt}, \quad N_{2}\left(x_{10}, y_{20}\right)=-\int_{0}^{\mathrm{t}} \mathrm{x}(\mathrm{t}) \mathrm{dt}$

Following the algorithm of NIM we obtain following approximations:

$\mathrm{x}_{11}=N_{1}\left(x_{10}, y_{20}\right)=\mathrm{t}-\sin t$

$\mathrm{y}_{21}=N_{2}\left(x_{10}, y_{20}\right)=1-e^{t}$

$\mathrm{x}_{12}=t-e^{t}+1$

$y_{22}=1-\frac{1}{2} t^{2}-\cos t$

$\mathrm{x}_{1 \mathrm{a}}=t-\sin t-\frac{1}{6} t^{3}$

$y_{2 a}=e^{t}-t-\frac{1}{2} t^{2}-1$

The solution in the series form is

$x(t)=1+t+\frac{1}{6} t^{3}-\frac{1}{60} t^{5}$

$y(t)=-t-\frac{1}{12} t^{4}$

Example 3; Consider the system of nonhomogeneous differential equations as

$\frac{d x}{d t}=z(t)-\cos _{x}$
$\frac{d y}{d t}=z(t)-e^{t}{ }_{x}$
$\frac{d z}{d t}=x(t)-y(t)$.

The conditions are as $\quad x(0)=1, y(0)=0, z(0)=2$,

The corresponding integral equations are as follows

$x(t)=1-\sin t+\int_{0}^{t} z(t) d t$

$$
\begin{aligned}
& y(t)=1-\mathrm{e}^{\mathrm{t}}+\int_{0}^{\mathrm{t}} \mathrm{z}(\mathrm{t}) \mathrm{dt} \\
& z(t)=2+\int_{0}^{\mathrm{t}}(\mathrm{x}-\mathrm{y}) \mathrm{dt} \\
& \text { Setting } x_{10}=1-\sin t, y_{20}=1-\mathrm{e}^{\mathrm{t}}, \mathrm{z}_{\mathrm{a} 0}=2 \text {, and } \\
& N_{1}\left(x_{10}, y_{20}, z_{a 0}\right)=\int_{0}^{\mathrm{t}} \mathrm{z}(\mathrm{t}) \mathrm{dt}, \\
& N_{2}\left(x_{10}, y_{20}, z_{a 0}\right)=\int_{0}^{\mathrm{t}} \mathrm{z}(\mathrm{t}) \mathrm{dt}, \\
& N_{\mathrm{a}}\left(x_{10}, y_{20}, z_{\mathrm{a} 0}\right)=\int_{0}^{\mathrm{t}}(\mathrm{x}-\mathrm{y}) \mathrm{dt}
\end{aligned}
$$

Following the algorithm of NIM we obtain following approximations:

$$
\begin{aligned}
& \mathrm{x}_{11}=N_{1}\left(x_{10}, y_{20}, z_{20}\right)=2 \mathrm{t} \\
& y_{21}=N_{2}\left(x_{10}, y_{20}, z_{30}\right)=2 \mathrm{t} \\
& \mathrm{z}_{\mathrm{a} 1}=N_{\mathrm{a}}\left(x_{10}, y_{20}, z_{a 0}\right)=\cos \mathrm{t}+\mathrm{e}^{\mathrm{t}}-2 \\
& \mathrm{x}_{12}=\mathrm{e}^{\mathrm{t}}-2 t+\sin t-1 \\
& \mathrm{y}_{22}=\mathrm{e}^{\mathrm{t}}-2 t+\sin t-1 \\
& \mathrm{z}_{\mathrm{a2}}=0 \\
& \mathrm{x}_{1 \mathrm{a}}=0 \\
& \mathrm{y}_{2 \mathrm{a}}=0 \\
& \mathrm{z}_{\mathrm{ag}}=0
\end{aligned}
$$

The solution in the series form is

$x(t)=e^{t}$

$y(t)=\sin t$

$z(t)=\cos t+e^{t}$

Which is the exact solution.

\section{Conclusion}

In this study, we have solved the linear differential equations using new iterative method. The solution is obtained in series form and exact solution of some of them. The obtained results show the efficiency of the method. Using NIM the calculation size is also reduced, which shows that the method is efficient and convenient.

\section{Acknowledgement}

The authors are very grateful to Assistant Prof. Dr.M. Jamil Amir and saraj khan niazi for his guidance support.

\section{References}

[1] N.Patil and A.Khambayat, "Differential Transform Method for system of Linear differential equations" Research journal of Mathematical and Statistical Science, Vol.2(3),4-6, March 201,pp.4-6

[2] E. Babolian, J. Biazar, A.R. Vahidi,(2004) Solution of a system of nonlinear equations by Adomian decomposition method, J. Math. Annal. Appl. 150, 847854

[3] N.Dogan (2012) Solution of the system of ordinary differential equations by combined laplace transformadomian decomposition method, Mathematical and computational Applications, Vol. 17, No.3, pp. 203-211

[4] K. Bathiha and B.Bathiha, A new algorithmfor solving linear ordinary differential equations" World Applied sciences journal, 15(12), 1777-1779, (2011) 
[5] T.Kamran,M.J.Amir, M.S.Rehman,"Solution of Eigen value problems by using new iterative method" International journal of scientific and engineering research,vol.6,issue 11,2015, pp 1355-1361

[6] M.S.Rehman, M.J.Amir, T.Kamran, "Using new iterative method to find the solution for a class of stiff systems of equations" International journal of Mathematics and physical sciences Research,vol.3.issue 2.2016,pp 60-65

[7] C. H. Hsiao and W. J. Wang, "Haar Wavelet Approach to Non-Linear Stiff Systems," Mathematics and Computer in Simulation, Vol. 57, No. 6, 2001, pp. 347353.

[8] Varsha Daftardar-Gejji, Hossein Jafri, An iterative method for solving nonlinear functional equations, $J$. Math. Appl. 316, 2006, 753-763.

[9] Sachin Bhalekar,Varsha Daftardar-Gejji, New iterative method: Application to partial differntial equations, Appl. Math. Comput. 203, 2008, 778-783.

[10] V. Daftardar-Gejji and S. Bhalekar, Solving fractional boundary value problems with Dirichlet boundary conditions using a new iterative method, Computers \& Mathematics with Applications 59, 2010, 1801-1809.

[11] V. Daftardar-Gejji and S. Bhalekar, An Iterative method for solving fractional differential equations, Proceedings in Applied Mathematics and Mechanics 7 (2008), 2050017-050018.

[12] S. Bhalekar and V. Daftardar-Gejji, Solving evolution equations using a new iterative method, Numerical Methods for Partial Differential Equations 26,2010, 906-916.

[13] M. Yaseen and M. Samraiz, A modified new iterative method for solving linear and nonlinear Klein-Gordon Equations, Appl. Math. Sci.6, 2012, 2979-2987.

\section{Author Profile}

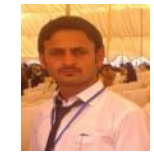

Muhammad Shafeeq Ur Rehman received the B.S. degree in Mathematics from University of Sargodha in 2012 and currently serving as SSE at Govt. Taleem ul Islam High School Chenab Nagar (chiniot). Doing his M.S. and working as home researcher. 